\title{
Measurement of Lactate Content and Amide Proton Transfer Values in the Basal Ganglia of a Neonatal Piglet Hypoxic-Ischemic Brain Injury Model Using MRI
}

\author{
(D) Y. Zheng and (D) X.-M. Wang
}

\begin{abstract}
BACKGROUND AND PURPOSE: As amide proton transfer imaging is sensitive to protein content and intracellular pH, it has been widely used in the nervous system, including brain tumors and stroke. This work aimed to measure the lactate content and amide proton transfer values in the basal ganglia of a neonatal piglet hypoxic-ischemic brain injury model by using MR spectroscopy and amide proton transfer imaging.
\end{abstract}

MATERIALS AND METHODS: From 58 healthy neonatal piglets (3-5 days after birth; weight, 1-1.5 kg) selected initially, 9 piglets remained in the control group and 43 piglets, in the hypoxic-ischemic brain injury group. Single-section amide proton transfer imaging was performed at the coronal level of the basal ganglia. Amide proton transfer values of the bilateral basal ganglia were measured in all piglets. The ROI of MR spectroscopy imaging was the right basal ganglia, and the postprocessing was completed with LCModel software.

RESULTS: After hypoxic-ischemic insult, the amide proton transfer values immediately decreased, and at $0-2$ hours, they remained at their lowest level. Thereafter, they gradually increased and finally exceeded those of the control group at 48-72 hours. After hypoxicischemic insult, the lactate content increased immediately, was maximal at 2-6 hours, and then gradually decreased to the level of the control group. The amide proton transfer values were negatively correlated with lactate content $(r=-0.79, P<.05)$.

CONCLUSIONS: This observation suggests that after hypoxic-ischemic insult, the recovery of $\mathrm{pH}$ was faster than that of lactate homeostasis.

ABBREVIATIONS: APT = amide proton transfer; APTw = amide proton transfer-weighted; $\mathrm{HI}=$ hypoxic-ischemic; $\mathrm{HIBI}=$ hypoxic-ischemic brain injury

$\mathbf{T}$ he neonatal brain is in a process of continuous development and maturation and has a great demand for oxygen. Normally, brain activities are primarily supported by energy produced from the aerobic metabolism of glucose. ${ }^{1-3}$ In a physiologic state, $90 \%-95 \%$ of brain energy is consumed by neurons, but $80 \%$ of glucose use happens in astrocytes, which suggests that a glucose mesostate released by astrocytes is absorbed and used by neurons to support their high energy consumption. A study ${ }^{4}$ has shown that during glucose metabolism in the brain, lactate is a carrier of energy and facilitates interaction between astrocytes and neurons. Astrocytes absorb glucose and transform it into lactate and then provide lactate to neurons. Therefore, lactate is an important mesostate during energy metabolism in the brain.

Received September 7, 2016; accepted after revision November 6.

From the Department of Radiology, Shengjing Hospital of China Medical University, Shenyang, PR China.

This study was supported by the National Natural Science Foundation of China (No. 30570541, 30770632, 81271631).

Please address correspondence to Xiao-Ming Wang, MD, Department of Radiology, Shengjing Hospital of China Medical University, No. 36, Sanhao St, Heping District, Shenyang 110004, PR China; e-mail: wangxm024@163.com; @little_yangyang

-- Indicates open access to non-subscribers at www.ajnr.org

http://dx.doi.org/10.3174/ajnr.A5066
Normally, this astrocyte-neuron-lactate shuttle maintains a dynamic balance. However, when the brain is exposed to a hypoxicischemic (HI) environment, aerobic energy metabolism is interrupted $^{5-7}$ and becomes anaerobic. During anaerobic metabolism, lactate is produced, causing an increase of lactate in brain tissue. As a result, the accumulated lactate suppresses glucose metabolism and uses up adenosine triphosphate, thus exacerbating intracellular acidosis. ${ }^{8,9}$ Meanwhile, lactate is a crucial substrate for neurons that restores aerobic energy metabolism after an $\mathrm{HI}$ insult and plays an important role in the early stage of HI insult. Therefore, the study of lactate metabolism changes in the brain after $\mathrm{HI}$ insult furthers the understanding of neuronal energy metabolism and post-hypoxic-ischemic brain injury (HIBI) neuronal energy recovery and neuron protection mechanisms.

Brain acidosis often occurs after HI insult, for which the adjustment of the brain $\mathrm{pH}$ is critical. $\mathrm{pH}$ is especially important for protein structure and enzyme activity in the brain. Therefore, it is essential to timely detect and regulate the intracellular $\mathrm{pH}$ of brain tissues.

Amide proton transfer (APT) imaging is a recently developed MR imaging technique. In theory, APT signal intensity primarily 


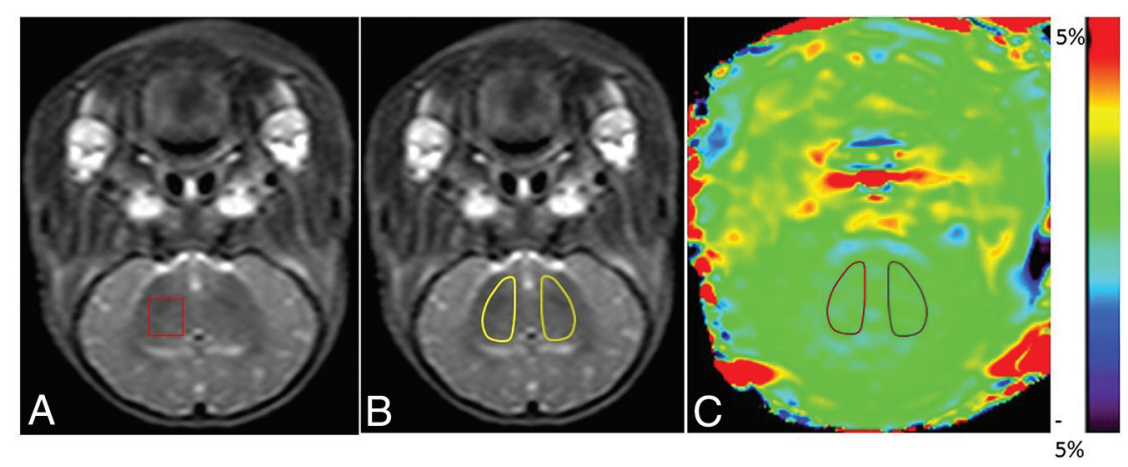

FIG 1. Definition of ROls in MR spectroscopy and APT images. A, Illustration of the ROI in MR spectroscopy. For all animals, the right basal ganglia were selected as the ROI. $B$ and $C$, Illustrations of ROIs in APT images (the T2WI serves as reference for the selection of ROIs in this study). In the control and HIBI groups, the bilateral basal ganglia were selected as ROls, as shown by the areas marked with a solid line in $B$ and $C$.

depends on the exchange rate between amide protons and water protons ${ }^{10-12}$; this exchange rate is associated with the protein content, $\mathrm{pH}$, and temperature. If it is assumed that other variables remain unchanged, when the $\mathrm{pH}$ decreases, the exchange rate slows and APT signal intensity weakens. ${ }^{13-15}$ Thus, APT imaging can also be considered $\mathrm{pH}$-weighted imaging. The magnetization transfer ratio asymmetry $(3.5 \mathrm{ppm})$ is called the amide proton transfer-weighted (APTw) intensity, to reflect the APT effect, which is contaminated by the conventional magnetization transfer ratio asymmetry and nuclear Overhauser enhancement.

In the normal physiologic state, lactate is absent or rare, ${ }^{16}$ but in an HI environment, lactate is increased; this change indicates enhanced anaerobic metabolism. To date, studies that explore the role of lactate in energy metabolism, particularly in neuron recovery after hypoxic-ischemic brain injury, and investigate the noninvasive detection of intracellular $\mathrm{pH}$ in brain tissues are few but promising. In the present study, we simulated pathophysiologic changes by using a neonatal piglet HIBI model and simultaneously evaluated the time course of lactate and APT changes in hypoxic-ischemic injury.

\section{MATERIALS AND METHODS \\ Experimental Animals}

Initially, 58 healthy piglets (Yorkshire piglets or Large White pigs, 3-5 days after birth; weight, 1-1.5 kg) were selected; then, 6 animals were excluded because of in-process death, modeling failure, and motion artifacts. Data were collected from the remaining 52 animals, and they were randomly assigned to the control group $(n=9)$ and model group $(n=43)$. On the basis of the MR imaging time after the HI procedure, the model group was further divided into 6 subgroups ( $0-2$ hours, $n=8$; 2-6 hours, $n=8$; $6-12$ hours, $n=6$; $12-24$ hours, $n=10 ; 24-48$ hours, $n=5$; and $48-72$ hours, $n=6$ ). All experiments in animals were performed in compliance with the Regulations for the Administration of Affairs Concerning Experimental Animals (http://www.asianlii.org/ cn/legis/cen/laws/rftaoacea704/) and Measures for the Administration of Licenses Concerning Experimental Animals (http://www.chinalawedu.com/news/23223/23228/24345.htm).

\section{Establishment of Experimental Models}

Control Group. In the operating room with a temperature of $28^{\circ} \sim 30^{\circ} \mathrm{C}, 0.6$ $\mathrm{mL} / \mathrm{Kg}$ of Su-mian-xin, ${ }^{16}$ an anesthetic agent (Changchun Military Veterinary Institute, Academy of Military Medical Science, Beijing, China), was intramuscularly injected; then tracheal intubation (2.5-mm cannula) was performed, and the tracheal intubation was connected to a TKR-200C small-animal ventilator (Jiangxi TELI Anesthesia \& Respiration Equipment, Jiangxi Province, China) for mechanical ventilation (100\% oxygen ventilator parameters: inspiratory/expiratory ratio, 1:1.5; respiratory frequency, 30 breaths/minute; pressure, $0.05-0.06 \mathrm{MPa}$ ). The heart rate and blood oxygen saturation were monitored with a TuffSat hand-held pulse oximeter (GE Healthcare, Milwaukee, Wisconsin). A catheter was inserted via an ear vein and then fixed in position. Thereafter, the neck skin was disinfected with iodophors, a median incision was made, and the bilateral common carotid arteries were isolated. Finally, the incision was sutured. During the operation, the piglet's body was covered with a quilt. After the surgery was completed, it was immediately put into an incubator (Shenzhen Reward Life Technology 912-005; Guangdong Province, China). Rectal temperature was maintained between $38^{\circ}$ and $40^{\circ} \mathrm{C}$.

HIBI Model Group. The same procedures as in the control group were performed on model piglets. In addition, when their statuses became stable after 30 minutes of rest, the bilateral common carotid arteries were clamped with artery clamps to occlude blood flow and 6\% oxygen was mechanically delivered (Dalian Special Gases, Liaoning Province, China) for 40 minutes; then 100\% oxygen (Dalian Special Gases) was inhaled, the blood supply of bilateral common carotid arteries was restored, and the neck incision was sutured. After the model was established, the piglet was put into the incubator. The heart rate and blood oxygen saturation were monitored throughout the process. Intraoperative and postoperative shock and convulsion were treated promptly. ${ }^{17,18}$ After the animals resumed spontaneous breathing, the ventilator was withdrawn.

\section{MR Imaging Protocol}

'H-MR Spectroscopy Scanning and Data Processing. The scanning was performed by using a 3T MR imaging scanner (Achieva 3.0T TX; Philips Healthcare, Best, the Netherlands) with pencil beams, second-order shimming, body coils for emission, and 8-channel head coils (sensitivity encoding) for receiving. MR spectroscopy was implemented with a point-resolved spectroscopy single-voxel sequence, and the sequence was performed with the following parameters: TR/TE $=2000 / 37 \mathrm{~ms}$, number of signal averaged $=64, \mathrm{VOI}=10 \mathrm{~mm} \times 10 \mathrm{~mm} \times 10 \mathrm{~mm}$. The right basal ganglia were selected as the ROI (Fig $1 A$ ). Before scanning, fluid attenuation and shimming were finished automatically by the scanner. Conventional MR imaging was performed before MR spectroscopy to obtain T1WI and T2WI for brain morphology 


\begin{tabular}{lccccccc}
\hline & & \multicolumn{5}{c}{ Model Group } \\
\cline { 2 - 7 } Parameters & Control & 0-2 Hours & 2-6 Hours & 6-12 Hours & 12-24 Hours & 24-48 Hours & 48-72 Hours \\
\hline APT (\%) & $0.50 \pm 0.12$ & $-0.46 \pm 0.25$ & $0.02 \pm 0.14$ & $0.26 \pm 0.04$ & $0.47 \pm 0.09$ & $0.80 \pm 0.11$ & $1.31 \pm 0.43$ \\
Lactate & $0.43 \pm 1.30$ & $3.78 \pm 4.31$ & $20.45 \pm 5.28$ & $13.07 \pm 1.10$ & $2.31 \pm 1.55$ & $0.16 \pm 0.25$ & $0.51 \pm 0.86$ \\
\hline
\end{tabular}

observation and MR spectroscopy positioning. After $\mathrm{HI}$ insult, MR imaging was performed at the time points specified for each group (time $=0$ was defined as control group). The raw image data were postprocessed by Linear Combination Model (LCModel; http://www.lcmodel.com/) software. ${ }^{19}$ NAA is at $2.02 \mathrm{ppm}$; Cr, at $3.02 \mathrm{ppm}$; Cho, at $3.2 \mathrm{ppm}$; and lactate, at $1.33 \mathrm{ppm}$. When MR imaging was performed, the piglet was carefully wrapped with a thick quilt to maintain body temperature. If spontaneous breathing was not restored after the operation, MR imaging was performed with artificial balloon breathing instead of mechanical ventilation. ${ }^{17,20,21}$

\section{APT Data Acquisition and Processing}

Acquisition of APT Data. The coil used for the APT experiments was the same as that used for the ${ }^{1} \mathrm{H}-\mathrm{MR}$ spectroscopy. All piglets were positioned at the level of the basal ganglia by using coronal T2WI. An off-resonance continuous-wave radiofrequency saturation pulse was used. APT single-section imaging was performed, and the saturation time, at $2 \mu \mathrm{T}$ excitation power, was $500 \mathrm{~ms}$ (the maximum time available for this body coil ${ }^{22-24}$ ). The acquisition mode was TSE, and the factor was 38 . We used the following settings: $\mathrm{TR}=4000 \mathrm{~ms}, \mathrm{TE}=8.1 \mathrm{~ms}$, matrix $=108 \times$ $71, \mathrm{FOV}=170 \mathrm{~mm} \times 145 \mathrm{~mm}$, section thickness $=5 \mathrm{~mm}$, scan time $=4$ minutes 16 seconds. For APT imaging, the multiacquisition method with multiple radiofrequency pulses was performed to enhance the signal-to-noise ratio. ${ }^{25}$ During acquisition, saturated radiofrequency pulses of 31 frequencies were acquired at different offsets from the water resonance frequency $(0, \pm 0.25, \pm 0.5, \pm 0.75, \pm 1, \pm 1.5, \pm 2, \pm 2.5, \pm 3[2], \pm 3.25[4]$, $\pm 3.5[8], \pm 3.75[4], \pm 4[2], \pm 4.5, \pm 5, \pm 6 \mathrm{ppm})$, where the number in brackets represents the number of repeat acquisitions when different from 1 , and the images acquired without radiofrequency saturation served as normalized images. This acquisition protocol enabled the correction of the $\mathrm{B}_{0}$ field and the acquisition of APT images with a high SNR. When the experimental animals were scanned, a constant body temperature was maintained to avoid signal changes caused by temperature fluctuations.

Postprocessing of APT Data. The acquired APT raw data were imported into the IDL application (Research Systems, Boulder, Colorado) for analysis, measurement, and reconstruction of pseudocolor images. First, voxel-based Z-spectra were obtained and then fitted by using a 12-order polynomial to identify the trough of the $\mathrm{Z}$-spectrum and construct $\mathrm{B}_{0}$ heterogeneity; this process completed the field correction. In the corrected $\mathrm{Z}$-spectrum, the symmetric data points at $\pm 3.5 \mathrm{ppm}$ were selected for asymmetry analysis (magnetization transfer ratio asymmetry, [3.5 $\mathrm{ppm}]=S_{\text {sat }}[-3.5 \mathrm{ppm}] / S_{0}-S_{\text {sat }}[+3.5 \mathrm{ppm}] / S_{0}$, where $S_{\text {sat }}$ denotes the signal intensity with the radiofrequency pulse and $S_{0}$ represents the signal intensity without the radiofrequency pulse).

APT Imaging: Selection of ROIs. After the raw data were analyzed automatically by the software, the acquired APT images were eval- uated by 2 senior radiologists and then quantified. After we combined the conventional coronal T2WI, ROIs (bilateral basal ganglia, Fig $1 B$ ) were manually drawn carefully on the APT images. The APT value of this ROI indicates the signal intensity. The ROIs should avoid the interference of the skull, CSF, and cerebral ventricles.

\section{Statistical Analysis}

The statistical analysis of data was performed by using SPSS for Windows (Version 17.0; IBM, Armonk, New York). Data were presented as mean $\pm \mathrm{SD}(\bar{X} \pm \mathrm{SD})$. The difference in APT values between the left and right basal ganglia was analyzed with the independent-samples $t$ test. The statistical differences in APT values and lactate content between the control and HIBI groups at different time points were analyzed by ANOVA. The correlation between APT values and lactate content was analyzed by Spearman rank correlation analysis. $P<.05$ was a statistically significant difference.

\section{RESULTS}

\section{Measurements of APT Values and Lactate Content}

Because no statistical difference in APT values was observed between the left and right basal ganglia $(P=.82)$, APT values of the bilateral basal ganglia were averaged to calculate a mean APT value for each group. The APT values of the control group and HIBI groups differed significantly (control group versus 6-12 hours, $P=.029$; control group versus $24-48$ hours, $P=.009$; other groups, $P<.001)$ except for control group versus the 12 - to 24 -hour group $(P=.762)$. The time-related changes of APT values in the control and HIBI model groups are shown in the Table and Fig 2.

\section{${ }^{1}$ H-MR Spectroscopy}

In the HIBI group, lactate content was maximal at 2-6 hours; thereafter, it gradually decreased and finally was similar to that of the control group, as shown in the Table and Fig 3. The lactate content of the control and HIBI groups did not differ significantly at 12-24 hours, 24-48 hours, or 48-72 hours (control versus 12-24 hours, $P=.16$; control versus $24-48$ hours, $P=.87$; and control versus $48-72$ hours, $P=.96)$, but it differed significantly at other time points $(0-2$ hours versus the control group, $P=.02$; 2-6 hours and 6-12 hours versus the control group, $P<.001$ ). The lactate content at different time points is presented as $\bar{X} \pm \mathrm{SD}$, as shown in the Table.

MR images and spectra fitted by the LCModel of the control and HIBI groups are shown in Figs 4 and 5.

\section{Correlation between APT Values and Lactate Content}

Time-related changes of APT values and lactate content are shown in Fig 6. APT values decreased at $0-2$ hours and thereafter 


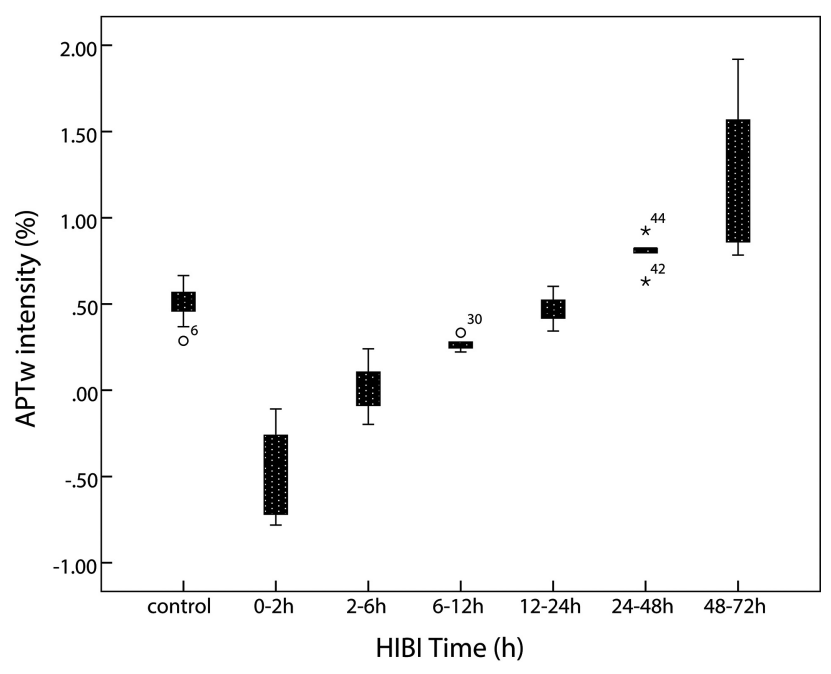

FIG 2. Time-related changes of APT values of the basal ganglia. After $\mathrm{HI}$ insult, APT values immediately decrease and reach the lowest level at $0-2$ hours; thereafter, the values gradually increase, recover to the level of the control group at 12-24 hours, and then continue increasing. They are higher than the control group level at 48-72 hours.

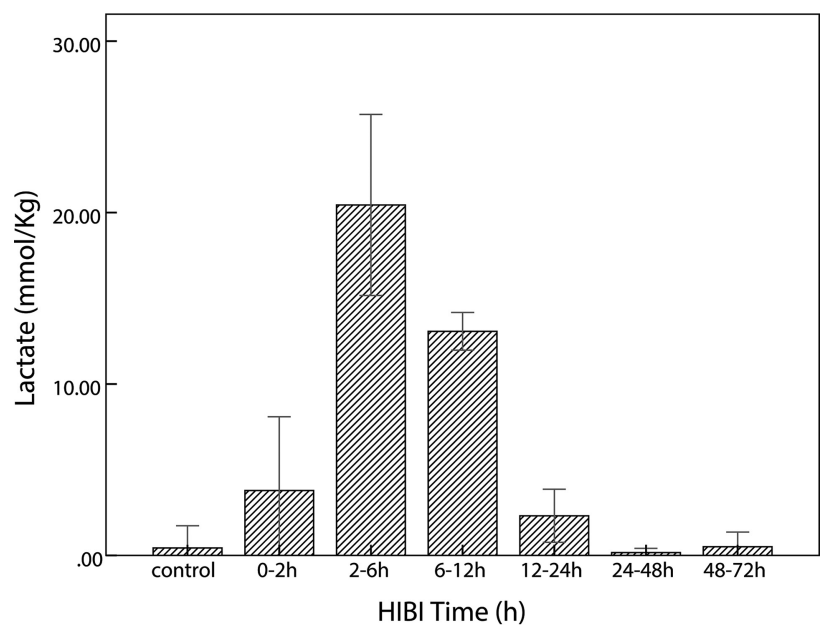

FIG 3. Time-related changes of lactate in the control and HIBI groups. After $\mathrm{HI}$ insult, lactate increases immediately, reaches maximal value at 2-6 hours, and thereafter decreases gradually; in the HIBI model group, lactate is similar to that of the control group at 48-72 hours after $\mathrm{HI}$ injury.

increased; lactate content continued increasing at 2-6 hours and thereafter trended toward decreasing.

As shown by Spearman rank correlation test, the APT values were negatively correlated with lactate content $(r=-0.79, P=.036)$.

\section{DISCUSSION}

HIBI is a hypoxic-ischemic brain impairment caused by many factors during the perinatal period and also a type of reperfusion brain injury after HI insult of the whole brain. The brain tissues undergo a series of pathophysiologic changes in the transition from hypoperfusion to reperfusion. Therefore, it is essential to develop a noninvasive neonatal MR imaging examination technique to evaluate molecular pathophysiologic changes of the brain after an HI procedure. In a study of middle cerebral artery occlusion in mouse models, Zhou et $\mathrm{al}^{10,26}$ found a marked change in $\mathrm{pH}$ in lesions before and after ischemic insult, but no

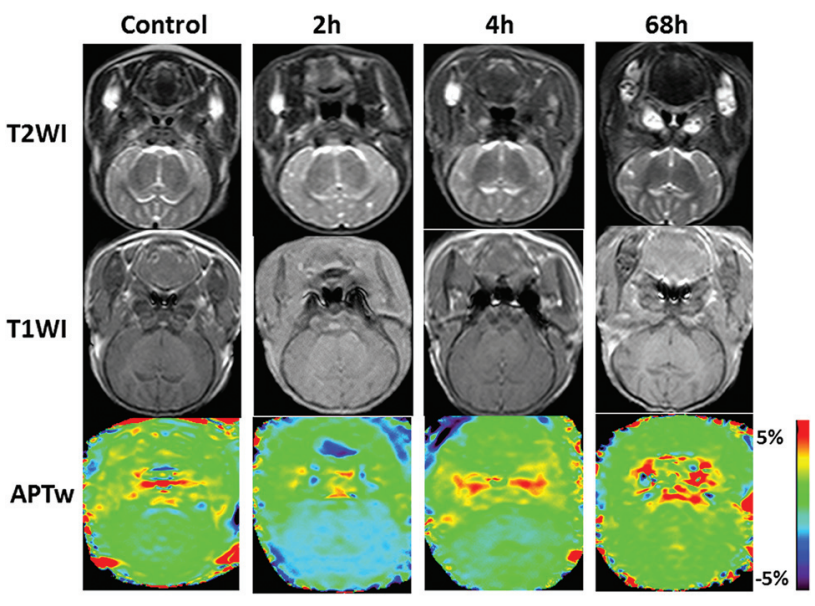

FIG 4. Coronal TIWI, T2WI, and APT scans at the basal ganglia area in the control and the model groups ( 2 hours, 4 hours, and 68 hours after hypoxia-ischemia reperfusion). The APT signal demonstrates the hypointensity at 2 hours after $\mathrm{HI}$, and then the signal gradually increases.

obvious variation in amide content was found during a short period. The exchange rate decreasing $50 \%-70 \%$ with a $\mathrm{pH}$ decrease of $0.5 \mathrm{U}$ supports the application of APT imaging in $\mathrm{HI}$ insult.

Our study results showed that after HI injury, APT values trended toward decreasing sharply at first (Table and Fig 2); if it is assumed that the protein content and temperature in the brain remains unchanged for a short period after $\mathrm{HI}$ insult, the change of APT signal may be primarily related to $\mathrm{pH}$ changes. Such a signal change reflects a reduction of intracellular $\mathrm{pH}$ in brain tissues within a short time after HI insult, primarily depending on acidosis secondary to aerobic dysmetabolism caused by $\mathrm{HI}$ insult (aerobic dysmetabolism refers to glucose metabolic disturbances, and the acidosis related to $\mathrm{HI}$ leads to an increase in anaerobic metabolism; it is not a dysmetabolism of the mitochondria, but a change in cellular processes). Intracellular acidosis is not only caused by lactate accumulation but also attributed to the aerobic dysmetabolism of glucose that occurs in the acute stage of $\mathrm{HI}$ insult. Furthermore, the cell membrane is unable to maintain the normal ion pump function that leads to intracellular $\mathrm{H}^{+}$retention in the early stage of HIBI. ${ }^{10}$ Subsequently, APT values gradually increased and recovered to the level of the control group at 12-24 hours. Such recovery of APT values is achieved by $\mathrm{pH}$ normalization after HI reperfusion, perhaps because locally accumulated metabolites are excreted by reperfusion, accompanied by the restoration of aerobic metabolism. The intracellular $\mathrm{pH}$ in mammal brain tissue is 7.2-7.3, and the extracellular $\mathrm{pH}$ is 7.3-7.4. ${ }^{27-29}$ The intracellular $\mathrm{pH}$ in $\mathrm{HI}$ brain tissue can impact cell survival and brain tissue outcomes. Studies have shown that when brain tissue undergoes $\mathrm{HI}$ injury, $\mathrm{pH}$ decreases transiently and then increases, inducing rebound alkalosis. Patients with alkalosis have a poor prognosis. ${ }^{30-33}$ Furthermore, an in vivo trial revealed that neuronal protection could be achieved by timely intervention to treat alkalosis. ${ }^{27}$

When the brain experiences HI insult, the relevant signaling pathways in astrocytes are activated, and lactate, as an important neurotransmitter, can regulate energy metabolism and secrete neuroprotective substances to achieve neuron protection through a series of biochemical changes and has a regulatory effect on cell 

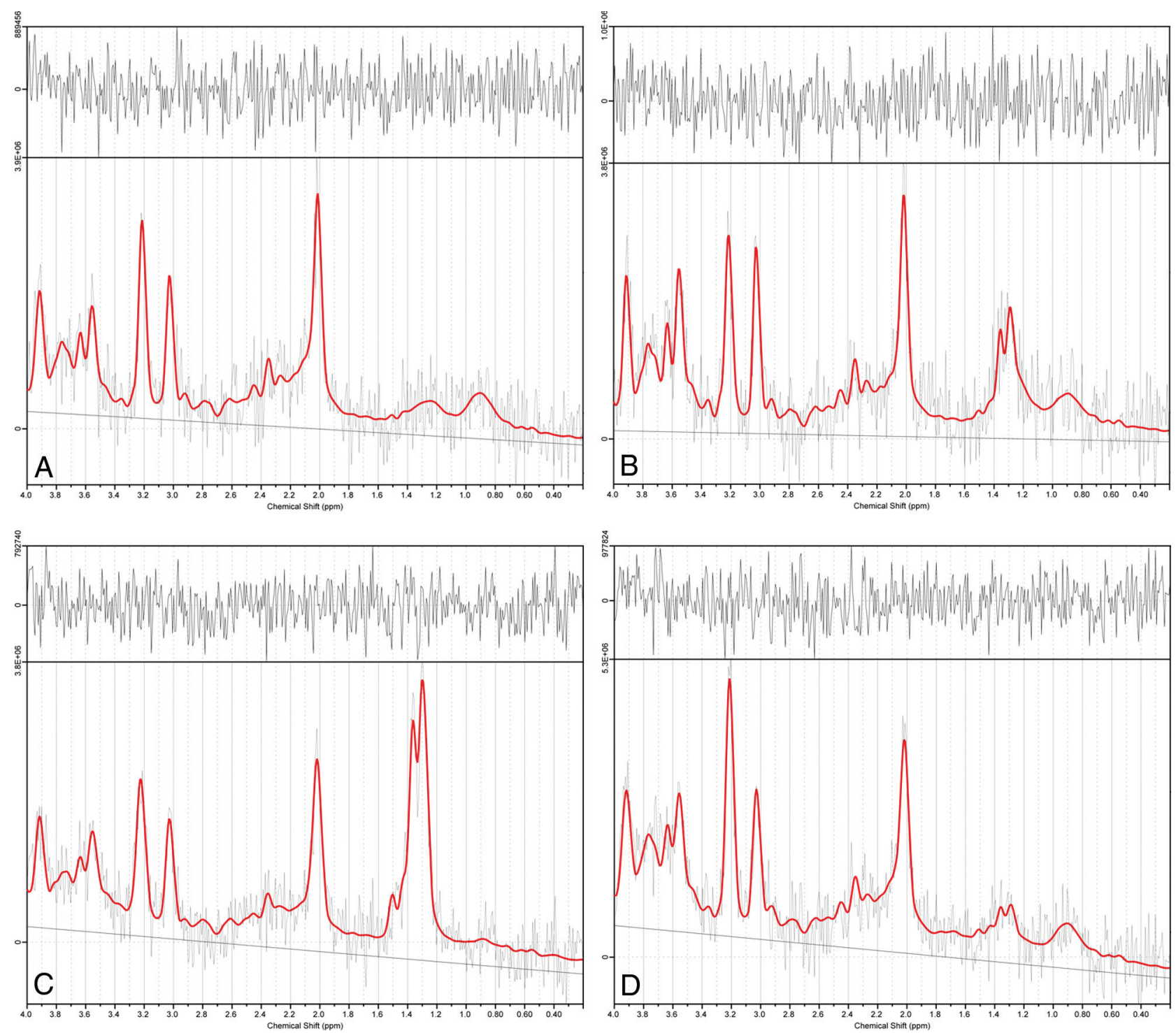

FIG 5. Results of ${ }^{1} \mathrm{H}-\mathrm{MR}$ spectroscopy data at selected time points in sample data analyzed by LCModel software. $A-D$, ${ }^{1} \mathrm{H}-\mathrm{MR}$ spectroscopy spectral curves of the right basal ganglia analyzed by LCModel in the control group and the HIBI group at 2 hours, 4 hours, and 68 hours, respectively. At 2 and 4 hours after $\mathrm{HI}$ insult, the lactate peaks (1.2-1.4 ppm) are markedly elevated, showing an upright single-peak or doublepeak change; at 68 hours, the lactate peak is lower but still higher than that of the control group.

apoptosis. $^{34,35}$ Lactate can be transmitted and absorbed via monocarboxylic acid transporters between astrocytes and neurons to provide the substrate of energy metabolism for neuronal activities. ${ }^{36-38}$ Thus, lactate produced by glycolysis is transmitted out of astrocytes via monocarboxylic acid transporter- 4 on the cell membrane, accumulates in the extracellular spaces, is then absorbed by neurons via monocarboxylic acid transporter- 2 on neuronal membranes, is transformed into pyruvic acid via lactate dehydrogenase, and finally enters into the tricarboxylic acid cycle of aerobic metabolism.

An increase of lactate was observed in the early stage of HI insult (Table and Fig 3), which is an important sign of brain hypoxia-ischemia. This finding is consistent with that in a previous study. ${ }^{39}$ After reperfusion, lactate is gradually decreased due to both aerobic metabolism recovery and lactate excretion.

At the time of acute hypoxia-ischemia, it is assumed that the amide proton concentration and temperature remain constant, and the change of APT value is mainly affected by the $\mathrm{pH}$. This study found that APT values were gradually restored to normal 2 hours after reperfusion; lactate increased in the first 6 hours after reperfusion and gradually decreased thereafter. Moreover, this trend matches those in previous experimental study. ${ }^{12}$ We also found that there was a relative delay between the peak change in lactate and the lowest peak value of APT, which indicates that the removal of $\mathrm{H}^{+}$and lactate is not synchronous. This time delay was interpreted as the recovery of $\mathrm{pH}$ being earlier than the clearance of lactate after $\mathrm{HI}$ reperfusion. Discharge mechanisms of $\mathrm{H}^{+}$include $\mathrm{Na}^{+}-\mathrm{H}^{+}$exchange and $\mathrm{HCO}_{3}{ }^{-}$neutralization and other mechanisms. ${ }^{27}$ Thus, a possible reason for the rapid recovery of $\mathrm{pH}$ and the relatively slow removal of lactate was that glucose anaerobic glycolysis was conducted continuously after reperfusion and the removal of lactate was first transported out of the cell, and then carried out by the circulation. ${ }^{40,41}$ Nevertheless, this aspect needs to be further studied. 

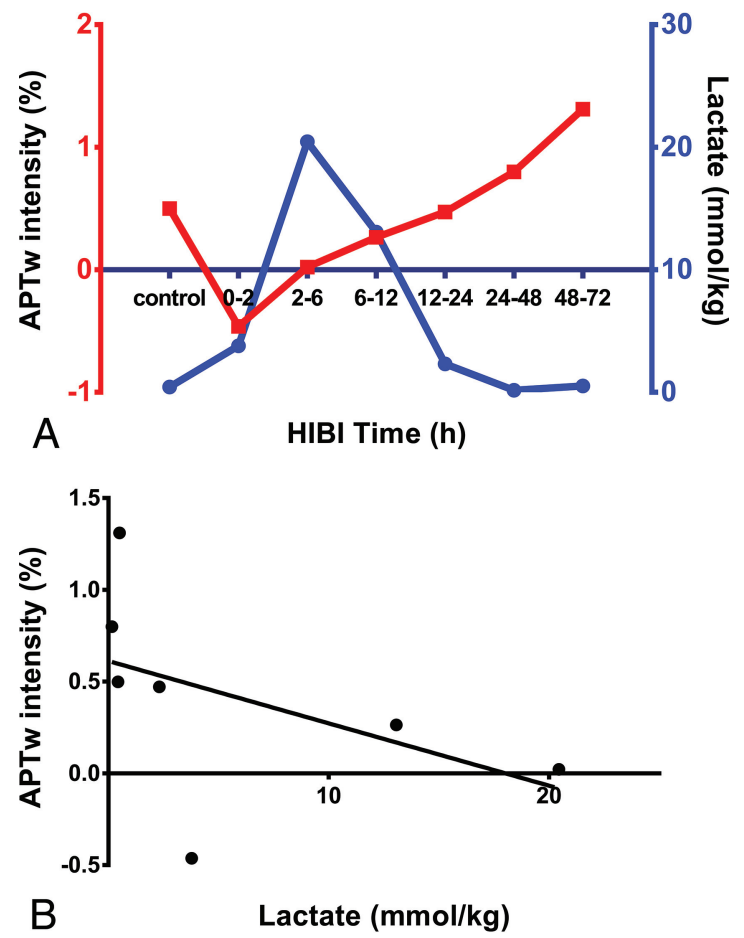

FIG 6. Changes and correlation between APT values and lactate content in basal ganglia of the HIBI model. A, The time-related changes in APTw intensity and lactate content are depicted in the same graph (the red square represents the APTw intensity at each time point; the blue circle denotes the lactate content at each time point). $B$, The correlation between APTw intensity and lactate content $(r=-0.79, P=.036)$.

In this study, the basal ganglia were selected as an ROI for both APT imaging and ${ }^{1} \mathrm{H}-\mathrm{MR}$ spectroscopy scanning because the basal ganglia are an area of high aerobic metabolism. ${ }^{42}$ Such an ROI can increase the sensitivity of biochemical tests and avoid the interference of lipids at the cerebral margin that influences the accurate measurement of lactate content. ${ }^{43}$

In the present study, there were some limitations: 1) The current APT imaging sequence used single-section imaging, and the coronal images of the basal ganglia were selected in this study, so HI injury of other parts and structures were not displayed and evaluated. 2) Due to limitations of anatomic structures, resolution, and other factors, only the basal ganglia were selected as ROIs, so other cerebral regions (eg, cerebral cortex, subcortical white matter, and hippocampus) were not evaluated. 3) Even though the magnetization transfer ratio asymmetry analysis (which can reduce the direct water saturation effect and semisolid magnetization transfer effect) was used, the APT effect was mixed with the nuclear overhauser enhancement. ${ }^{44}$ ) Only data from the right basal ganglia were acquired by single-voxel ${ }^{1} \mathrm{H}$-MR spectroscopy scanning, so bilateral tissues could not be compared and analyzed.

${ }^{1} \mathrm{H}-\mathrm{MR}$ spectroscopy data were postprocessed by using LCModel software, which effectively addresses issues such as baseline correction, spectral line decomposition, and accurate measurement of the absolute content of metabolites. ${ }^{45}$ The LCModel can automatically perform baseline correction, eddy current correction, and phase correction and provide an ideally fit spectral line. The Cramer-Rao Lower Bound estimating produced by the LCModel avoids extensive examination of each spectroscopic image and helps reject low-quality spectra (Fig 4). ${ }^{46}$ Studies $^{47,48}$ have suggested that the coefficient of variation of absolute substance content calculated by the LCModel is lower than that for the ratio of metabolites.

In this study, an acute HIBI model was established in piglets, in which the blood supply of the bilateral common carotid arteries was interrupted and then the reperfusion was simulated when the blood supply was restored; it facilitates the investigation of reperfusion injury. ${ }^{49-51}$ In this study, we simulated neonatal pathophysiologic changes by using a neonatal piglet HIBI model. The basal ganglia injury shown on MR imaging was consistent with histologic changes; therefore, this model is suitable for acute and subacute experimental studies. ${ }^{16,17}$ The results indicate that this model is suitable for molecular imaging studies. Compared with previous studies with a rat hypoxia-ischemia model, ${ }^{49,52,53}$ the neonatal pig brain sulcus and gyrus are obvious and similar to the human brain structure. At present, there is no report in the literature describing the use of a piglet hypoxia-ischemia model for APT imaging studies, to our knowledge. Our modeling method has high reproducibility and can provide reliable experimental results, though it is somewhat complex. APT and MR spectroscopy have been measured separately many times in different ischemic models; however, they have not been measured together as in this model. In fact, this relative delay between the peak change in lactate and the APT value is one of the main novel points of our work because it has not previously been observed.

\section{CONCLUSIONS}

In the present study, the changes in APTw intensity and lactate content show a relative time delay in their recovery stage, indicating that recovery of $\mathrm{pH}$ was faster than that of lactate.

\section{REFERENCES}

1. Amaral AI, Teixeira AP, Martens S, et al. Metabolic alteration induced by ischemia in primary cultures of astrocytes: merging $13 \mathrm{C}$ NMR spectroscopy and metabolic flux analysis. J Neurochem 2010; 113:735-48 CrossRef Medline

2. Dickey EJ, Long SN, Hunt RW. Hypoxic ischemic encephalopathy: what can we learn from humans? Vet Intern Med 2011;25:1231-40 CrossRef Medline

3. Lai MC, Yang SN. Perinatal hypoxic-ischemic encephalopathy. J Biomed Biotechnol 2011;2011:609813 CrossRef Medline

4. Schurr A, Payne RS. Lactate, not pyruvate, is neuronal aerobic glycolysis end product: an in vitro electrophysiological study. Neuroscience 2007;147:613-19 CrossRef Medline

5. Guo L, Wang D, Bo G, et al. Early identification of hypoxic-ischemic encephalopathy by combination of magnetic resonance (MR) imaging and proton MR spectroscopy. Exp Ther Med 2016;12:2835-42 CrossRef Medline

6. Malik GK, Pandey M, Kumar R, et al. MR imaging and in vivo proton spectroscopy of the brain in neonates with hypoxic ischemic encephalopathy. Eur J Radiol 2002;43:6-13 CrossRef Medline

7. Khong PL, Tse C, Wong IY, et al. Diffusion-weighted imaging and proton magnetic resonance spectroscopy in perinatal hypoxicischemic encephalopathy: association with neuromotor outcome at 18 months of age. J Child Neurol 2004;19:872-81 Medline

8. Wang H, Wang X, Guo Q. The correlation between DTI parameters and levels of AQP-4 in the early phases of cerebral edema after hypoxic-ischemic/reperfusion injury in piglets. Pediatr Radiol 2012; 42:992-99 CrossRef Medline 
9. Distefano G, Praticò AD. Actualities on molecular pathogenesis and repairing processes of cerebral damage in perinatal hypoxic-ischemic encephalopathy. Ital J Pediatr 2010;36:63 CrossRef Medline

10. Zhou J, Payen JF, Wilson DA, et al. Using the amide proton signals of intracellular proteins and peptides to detect $\mathrm{pH}$ effects in MRI. Nat Med 2003;9:1085-90 CrossRef Medline

11. Zhou J, Tryggestad E, Wen Z, et al. Differentiation between glioma and radiation necrosis using molecular magnetic resonance imaging of endogenous proteins and peptides. Nat Med 2011;17:130-34 CrossRef Medline

12. Jokivarsi KT, Gröhn HI, Gröhn OH, et al. Proton transfer ratio, lactate, and intracellular $\mathrm{pH}$ in acute cerebral ischemia. Magn Reson Med 2007;57:647-53 CrossRef Medline

13. Zhou J, Yan K, Zhu H. A simple model for understanding the origin of the amide proton transfer MRI signal in tissue. Appl Magn Reson 2012;42:393-402 CrossRef Medline

14. Sun PZ, Benner T, Copen WA, et al. Early experience of translating pH-weighted MRI to image human subjects at 3 Tesla. Stroke 2010; 41(10 suppl):S147-51 CrossRef Medline

15. Zhou J, Wilson DA, Sun PZ, et al. Quantitative description of proton exchange processes between water and endogenous and exogenous agents for WEX, CEST, and APT experiments. Magn Reson Med 2004;51:945-52 CrossRef Medline

16. Wang XY, Wang HW, Fu XH, et al. Expression of N-methyl-d-aspartate receptor 1 and its phosphorylated state in basal ganglia of a neonatal piglet hypoxic-ischemic brain injury model: a controlled study of (1)H MRS. Eur J Paediatr Neurol 2012;16:492-500 CrossRef Medline

17. Munkeby BH, De Lange C, Emblem KE, et al. A piglet model for detection of hypoxic-ischemic brain injury with magnetic resonance imaging. Acta Radiol 2008;49:1049-57 CrossRef Medline

18. LeBlanc MH, Qian XB, Cai ZW. The effect of glucose during ischemia on brain ATP, lactate, and glutamate in piglets. Biol Neonate 1997;72:243-54 CrossRef Medline

19. Katsura K, Asplund B, Ekholm A, et al. Extra- and intracellular $\mathrm{pH}$ in the brain during ischaemia: related to tissue lactate content in normo- and hypercapnic rats. Eur J Neurosci 1992;4: 166-76 CrossRef Medline

20. Vial F, Serriere S, Barantin L, et al. A newborn piglet study of moderate hypoxic-ischemic brain injury by $1 \mathrm{H}-\mathrm{MRS}$ and MRI. Magn Reson Imaging 2004;22:457-65 CrossRef Medline

21. McCulloch KM, Raju TN, Navale S, et al. Developing a long-term surviving piglet model of neonatal hypoxic-ischemic encephalopathy. Neurol Res 2005;27:16-21 CrossRef Medline

22. Zhao X, Wen Z, Zhang G, et al. Three-dimensional turbo-spin-echo amide proton transfer MR imaging at 3-Tesla and its application to high-grade human brain tumors. Mol Imaging Biol 2013;15:114-22 CrossRef Medline

23. Zhao X, Wen Z, Huang F, et al. Saturation power dependence of amide proton transfer image contrasts in human brain tumors and strokes at 3 T. Magn Reson Med 2011;66:1033-41 CrossRef Medline

24. Zhou J, Blakeley JO, Hua J, et al. Practical data acquisition method for human brain tumor amide proton transfer (APT) imaging. Magn Reson Med 2008;60:842-49 CrossRef Medline

25. Wen Z, Hu S, Huang F, et al. MR imaging of high-grade brain tumors using endogenous protein and peptide-based contrast. $\mathrm{Neu}$ roimage 2010;51:616-22 CrossRef Medline

26. Sun PZ, Zhou J, Sun W, et al. Detection of the ischemic penumbra using pH-weighted MRI. J Cereb Blood Flow Metab 2007;27:1129-36 CrossRef Medline

27. Uria-Avellanal C, Robertson $\mathrm{NJ} . \mathrm{Na}^{+} / \mathrm{H}^{+}$exchangers and intracellular pH in perinatal brain injury. Transl Stroke Res 2014;5:79-98 CrossRef Medline

28. Hamakawa H, Murashita J, Yamada N, et al. Reduced intracellular $\mathrm{pH}$ in the basal ganglia and whole brain measured by $31 \mathrm{P}-\mathrm{MRS}$ in bipolar disorder. Psychiatry Clin Neurosci 2004;58:82-88 CrossRef Medline
29. Casey JR, Grinstein S, Orlowski J. Sensors and regulators of intracellular pH. Nat Rev Mol Cell Biol 2010;11:50-61 CrossRef Medline

30. Hugg JW, Duijn JH, Matson GB, et al. Elevated lactate and alkalosis in chronic human brain infarction observed by $1 \mathrm{H}$ and 31P MR spectroscopic imaging. J Cereb Blood Flow Metab 1992;12:734-44 CrossRef Medline

31. Levine SR, Helpern JA, Welch KM, et al. Human focal cerebral ischaemia: evaluation of brain $\mathrm{pH}$ and energy metabolism with P-31 NMR spectroscopy. Radiology 1992;185:537-44 CrossRef Medline

32. Welch KM, Levine SR, Helpern JA. Pathophysiological correlates of cerebral ischaemia: the significance of cellular acid base shifts. Funct Neurol 1990;5:21-31 Medline

33. Robertson NJ, Cowan FM, Cox IJ, et al. Brain alkaline intracellular pH after neonatal encephalopathy. Ann Neurol 2002;52:732-42 CrossRef Medline

34. Brown AM, Ransom BR. Astrocyte glycogen and brain energy metabolism. Glia 2007;55:1263-71 CrossRef Medline

35. Mehta SL, Manhas N, Raghubir R. Molecular targets in cerebral ischemia for developing novel therapeutics. Brain Res Rev 2007;54: 34-66 CrossRef Medline

36. Chiry O, Fishbein WN, Merezhinskaya N, et al. Distribution of the monocarboxylate transporter MCT2 in human cerebral cortex: an immunohistochemical study. Brain Res 2008;1226:61-69 CrossRef Medline

37. Dienel GA, Hertz L. Astrocytic contributions to bioenergetics of cerebral ischemia. Glia 2005;50:362-88 CrossRef Medline

38. Hertz L, Dienel GA. Lactate transport and transporters: general principles and functional roles in brain cells. J Neurosci Res 2005;79: 11-18 CrossRef Medline

39. Mabe $\mathrm{H}$, Blomqvist $\mathrm{P}$, Siesjö BK. Intracellular $\mathbf{p H}$ in the brain following transient ischaemia. J Cereb Blood Flow Metab 1983;3:109-14 CrossRef Medline

40. Allen K, Busza AL, Crockard HA, et al. Acute cerebral ischaemia: concurrent changes in cerebral blood flow, energy metabolites, $\mathrm{pH}$, and lactate measured with hydrogen clearance and $31 \mathrm{P}$ and $1 \mathrm{H} \mathrm{nu}-$ clear magnetic resonance spectroscopy, III: changes following ischaemia. J Cereb Blood Flow Metab 1988;8:816-21 CrossRef Medline

41. Kauppinen RA, Williams SR. Cerebral energy metabolism and intracellular $\mathrm{pH}$ during severe hypoxia and recovery: a study using $1 \mathrm{H}$, $31 \mathrm{P}$, and $1 \mathrm{H}[13 \mathrm{C}]$ nuclear magnetic resonance spectroscopy in the guinea pig cerebral cortex in vitro. J Neurosci Res 1990;26:359-69 Medline

42. Zhu W, Zhong W, Qi J, et al. Proton magnetic resonance spectroscopy in neonates with hypoxic-ischemic injury and its prognostic value. Transl Res 2008;152:225-32 CrossRef Medline

43. Groenendaal F, Veenhoven RH, van der Grond J, et al. Cerebral lactate and $\mathrm{N}$-acetyl-aspartate/choline ratios in asphyxiated full-term neonates demonstrated in vivo using proton magnetic resonance spectroscopy. Pediatr Res 1994;35:148-51 CrossRef Medline

44. Ling W, Regatte RR, Navon G, et al. Assessment of glycosaminoglycan concentration in vivo by chemical exchange-dependent saturation transfer (gagCEST). Proc Natl Acad Sci U S A 2008;105:2266-70 CrossRef Medline

45. Provencher S. LCModel \& LCMgui User's Manual. November 23, 2016. http://lcmodel.ca/lcm-manual.shtml. Accessed December 13, 2016

46. Jiru F, Skoch A, Klose U, et al. Error images for spectroscopic imaging by LCModel using Cramer-Rao bounds. MAGMA 2006;19:1-14 CrossRef Medline

47. Atwood T, Payne VS, Zhao W, et al. Quantitative magnetic resonance spectroscopy reveals a potential relationship between radiation-induced changes in rat brain metabolites and cognitive impairment. Radiat Res 2007;168:574-81 CrossRef Medline

48. Verma A, Saraswat VA, Radha Krishna Y, et al. In vivo $\mathbf{1 H}$ magnetic resonance spectroscopy-derived metabolite variations between acute-on-chronic liver failure and acute liver failure. Liver Int 2008; 28:1095-103 CrossRef Medline 
49. Roohey T, Raju TN, Moustogiannis AN. Animal models for the study of perinatal hypoxic-ischemic encephalopathy: a critical analysis. Early Hum Dev 1997;47:115-46 CrossRef Medline

50. Zhang YF, Wang XY, Guo F, et al. Simultaneously changes in striatum dopaminergic and glutamatergic parameters following hypoxic-ischemic neuronal injury in newborn piglets. Eur J Paediatr Neurol 2012;16:271-78 CrossRef Medline

51. Zhang YF, Wang XY, Cao L, et al. Effects of hypoxic-ischemic brain injury on striatal dopamine transporter in newborn piglets: evalu- ation of 11C-CFT PET/CT for DAT quantification. Nucl Med Biol 2011;38:1205-12 CrossRef Medline

52. Seo H, Lim KH, Choi JH, et al. Similar neuroprotective effects of ischemic and hypoxic preconditioning on hypoxia-ischemia in the neonatal rat: a proton MRS study. Int J Dev Neurosci 2013;31:616-23 CrossRef Medline

53. Sun PZ, Zhou J, Huang J, et al. Simplified quantitative description of amide proton transfer (APT) imaging during acute ischemia. Magn Reson Med 2007;57:405-10 CrossRef Medline 